\title{
Beyond Compare: Art from Africa in the Bode Museum*
}

\author{
Reviewed by Kristin Otto
}

Beyond Compare: Art from Africa in the Bode Museum-a curatorial collaboration between Julien Chapuis, Jonathan Fine, and Paola Ivanov—is certainly not the first exhibition to place works from Africa in direct conversation, juxtaposition, and comparison with Western arts. "Primitivism" in Twentieth-Century Art: Affinity of the Tribal and the Modern (1984) at the Museum of Modern Art famously (or infamously) did so to examine the aesthetic inspirations and intersections between artistic movements. More recently, Picasso Primitif (2017) at the musée du quai Branly returned to this comparison with a more focused and direct look at Picasso's personal collection and sources of inspiration for his work (Monroe 2018). Although not employing European artworks, ART/artifact (1988) at the Center for African Art used a comparison of European exhibition methodologies to query the categories assigned to African objects. These landmark, comparative exhibitions provoked questions, controversy, and debates in the realm of museum practice. Is comparison inherent in any museum exhibition or display? And is comparison always hierarchical?

The curators of Beyond Compare in Berlin were certainly cognizant of the comparative exhibitions that have come before and the debates they have provoked. The opening textpresented in both German and English shortly after entering the grand hall of the museumimmediately addresses that museums invite comparison, but that comparison is "not neutral, but charged with socially defined prejudices, conventions, and constructions of history." With this in mind, the exhibit proposes to use the direct comparison of twenty-two pairs of African and European objects, along with more generally thematically grouped objects in a special exhibition gallery, to explore the interrelationships between African and European arts. The exhibition, prompted by the closing of the Ethnologisches Museum in preparation for the opening of the Humboldt Forum, uses the simultaneous display of African and European objects to explore the intersections of history, materials, artistry, use, meaning, and museum practice.

The first pairing, presented just after the entrance in the museum's grand basilica, is Putto with a Tambourine by Donatello and Statue of the Goddess Irhevbu or of Princess Edeleyo from the Kingdom of Benin. These set the tone for the remainder of the exhibition. When confronted with the visual similarities of the size and posture mirrored between the pair of bronze/brass figures staged side-by-side, it is impossible not to begin drawing comparisons. Rather than focusing merely on the obvious visual similarities, the accompanying exhibition text refreshingly uses the two objects to query how and why each were interpreted differently as art and cultural artifact, and then by extension accessioned in separate museum collections.

\footnotetext{
${ }^{*}$ This editorially reviewed contribution was accepted for publication in Museum Anthropology Review on February 11, 2019. The text is licensed under the Creative Commons Attribution 4.0 International License. To view a copy of this license, visit http://creativecommons.org/licenses/by/4.0/. Rights to images are retained by the Bode Museum.
} 




Figure 1. Unvergleichlich: Kunst aus Afrika im Bode-Museum, Ausstellungsansicht, (c) Staatliche Museen zu Berlin / David von Becker.

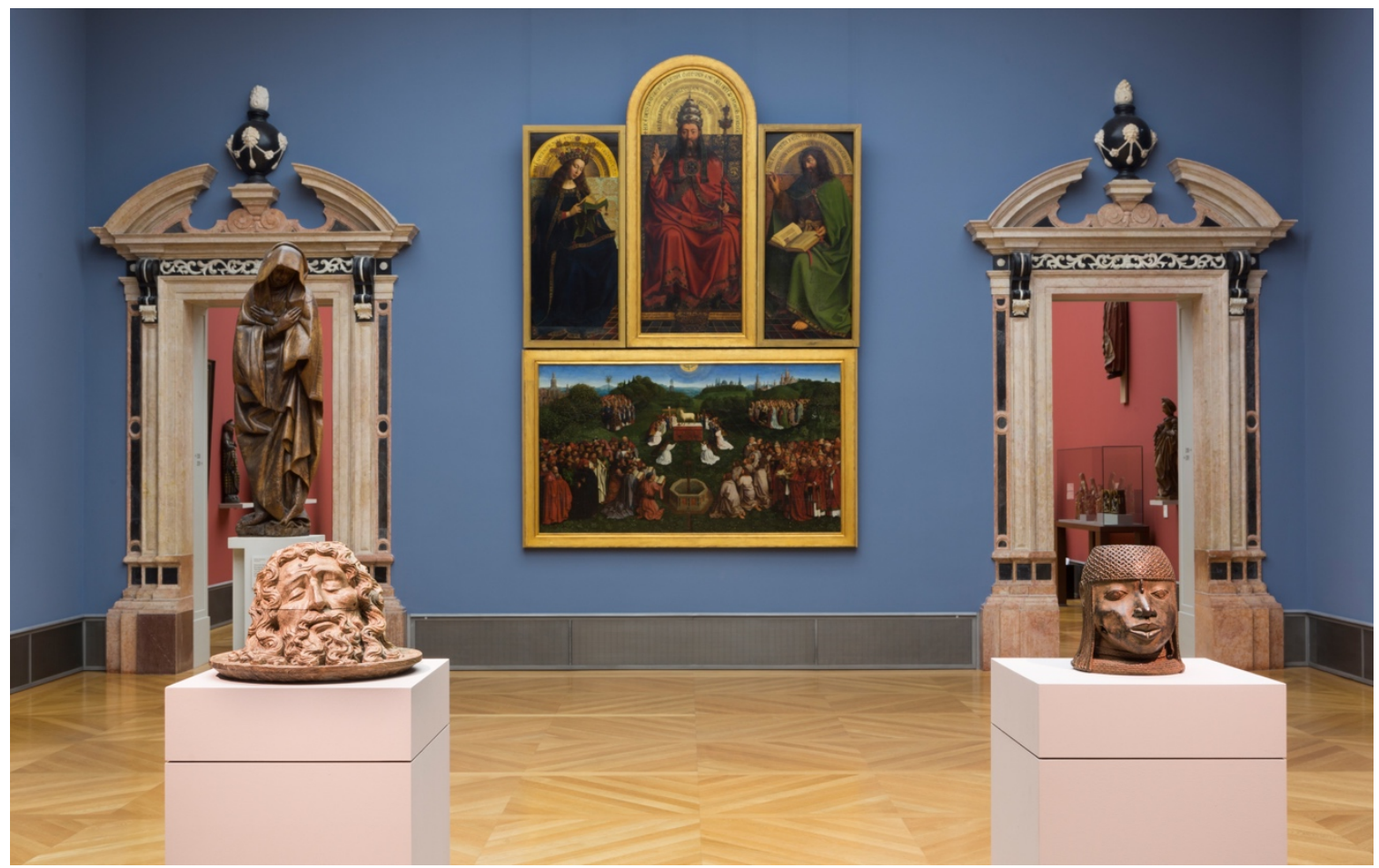

Figure 2. Unvergleichlich: Kunst aus Afrika im Bode-Museum, Ausstellungsansicht, (C) Staatliche Museen zu Berlin / David von Becker. 




Figure 3. Unvergleichlich: Kunst aus Afrika im Bode-Museum, Ausstellungsansicht, (C) Staatliche Museen zu Berlin / David von Becker.

As I set off on my November 2018 journey through Beyond Compare to explore the rest of these pairings, I found myself grateful that I had downloaded the accompanying exhibition app (Figures 1-6). This was not only because of the wealth of extra material I found inside, but also for the more practical need of navigating around the exhibit. Rather than being confined to one set space, the pairs of objects were dispersed throughout the Bode Museum galleries, with thematic groupings of objects located in the basement Special Exhibition Room. While wandering the halls of German Gothic or Italian Renaissance art would not have been an unwelcome experience, the maps, audio guide, and accompanying texts with suggested paths through the galleries to visit all the pairings provided by the app proved useful. Each pairing was easily identifiable by the bold, hot pink painted " $\mathrm{X}$ " on the labels, which was also present on all the promotional material for the exhibition. The architectural settings and design in the galleries made for some impressive and dramatic backdrops for the comparisons, while also thoroughly emphasizing the "Europeaness" of the exhibition context.

The pairings are too numerous to name individually, but I was particularly struck by groupings such as one on the theme of hair, which included a Chokwe wooden figure depicting a woman of rank alongside a 'virgin and child' figure known as the Dangolsheim Madonna by Nikolaus Gerhaert von Leyden. The Chokwe figure features real human hair, and the Madonna displays intricately carved curls. The main exhibition text discusses hair as a symbol of power and status as well as an expressive aesthetic element. From delving deeper into the app, I learned more about the theme of hair, including such topics as the possibility of the Madonna figure once housing relics of Mary's hair and the political misuse of hair in European and African relations. In another pairing themed around portraits, we see a 
commemorative sculpture of King Fosia, carved from wood, alongside Queen Jeanne de Navarre as a Donor, carved from limestone. The exhibition text describes how both images represent known royal figures, but their depictions are not entirely lifelike. They have been altered by abstraction and influenced by idealized expressions and postures. The display asks us to consider what is most important when inscribing people in public memory; physical appearance or symbolic identity?

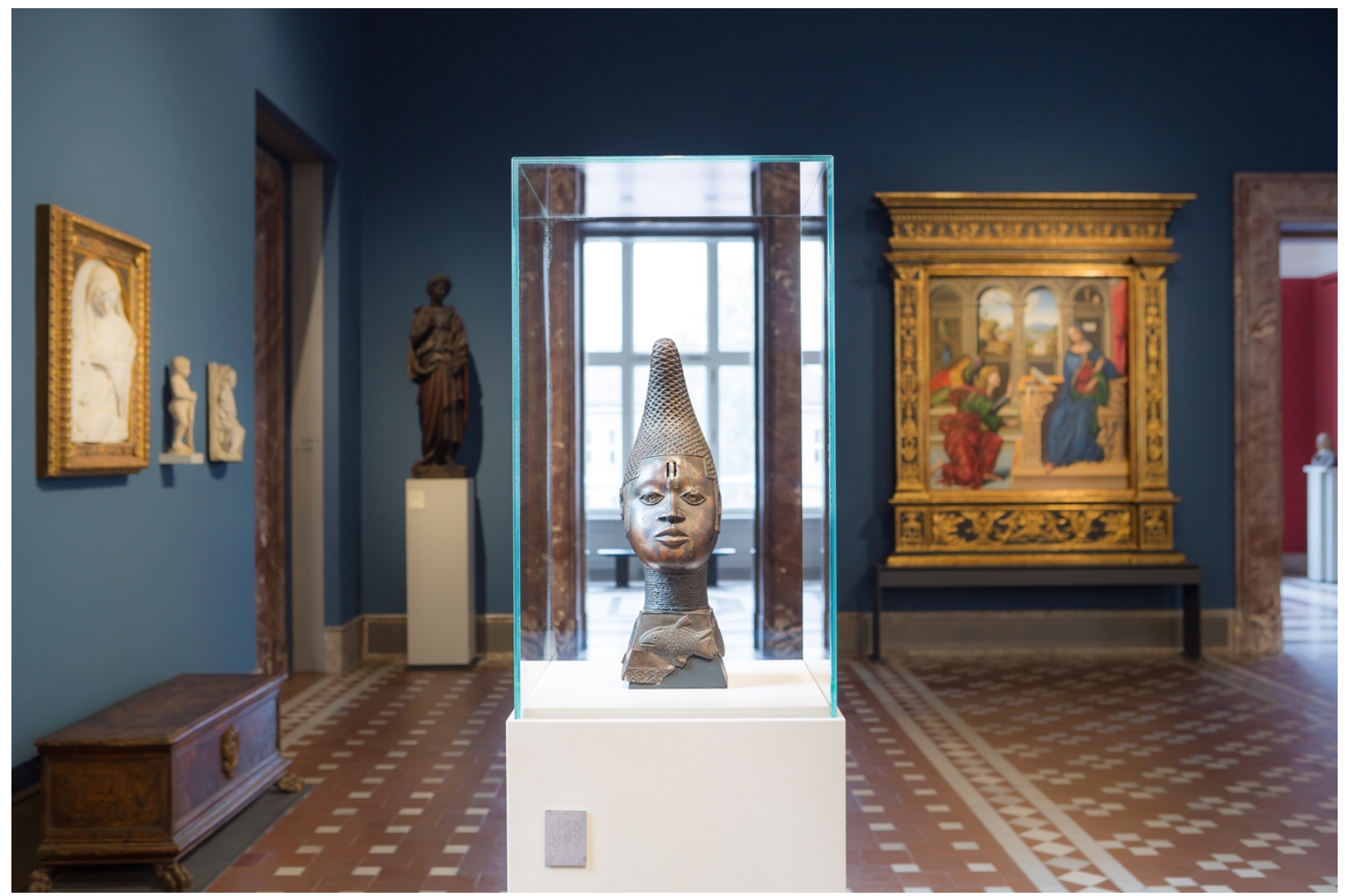

Figure 4. Unvergleichlich: Kunst aus Afrika im Bode-Museum, Ausstellungsansicht, (C) Staatliche Museen zu Berlin / David von Becker.

In addition to the pairings dispersed throughout the galleries, the exhibit also takes place in the lower level Special Exhibition Room. After traversing through the baroque architecture of the upper galleries, the change to the modern aesthetic of greys, metal, and stone floors was somewhat jarring. This, combined with the shift from the direct nature of the paired comparisons to a more free-flowing thematic arrangement, made this section somewhat more difficult to follow conceptually. However, the themes of aesthetics, others, gender, performance, protection and guidance, and death are all similarly well contextualized in the app. There were, of course, many standout objects in both the pairings and the thematic sections, and the incorporation of contemporary photography like Nomusa Makhubu's Umasifanisane I (2013) was a welcome addition to an already diverse display.

As mentioned, a particular strength of Beyond Compare's interpretation is the level of research that clearly went into the exhibit, shown most evidently in the exhibition app and 
accompanying catalog. Through the app, I could engage with anything from a video of restorers working on a mangaaka, to audio excerpts of curators like Jonathan Fine discussing depictions of slavery in European art, to images of associated objects in Berlin's other collections. This, along with the accompanying in-depth catalog essays (also published in English) describing the exhibition themes, stands as testament to the level of background research and contextualization backing this exhibit.



Figure 5. Unvergleichlich: Kunst aus Afrika im Bode-Museum, Ausstellungsansicht, (C) Staatliche Museen zu Berlin / David von Becker.

However, just as the exhibit shows us that comparison is unavoidable, it is also impossible to ignore the current climate of African collections in Europe. The exhibition features several of the more controversial objects in the current discussions of repatriation and restitution, including several bronzes from Benin. The controversy surrounding these objects is addressed in some sections, including the comparison of an oba head with a carving of John the Baptist's head, and the comparison of a lion aquamanile from Lower Saxony with a leopard aquamanile from Benin (Figure 2). However, outside of recognizing the violent acquisition of objects during the British "punitive expedition," and a discussion of misinterpretation of Benin oba heads as being associated with decapitation, the exhibition text does little to comment on the controversy. The visitor is left somewhat unsatisfactorily with the knowledge that some of the objects in the exhibit arrived in the museum's collection through controversial means, but not how the museum responds to this controversy. Given the sheer amount of information, interpretation, and question-based discussions focused on the political nature of museum interpretation in the exhibit, it was a noticeable absence. The 
current climate surrounding African arts in France means that the upcoming Humbolt Forum will likely have no choice but to respond and address these issues in a much more direct way in the near future (Sarr and Savoy 2018).

Beyond Compare is a bold approach to examining the intersections between European and African culture, history, and arts. It moves beyond the questions and implicit hierarchies of earlier exhibitions of premodern/modern and art/artifact to present the work of comparing as a process of creating open-ended dialogue, rather than closed categories. Furthermore, the exhibition style of direct comparison with accompanying text and materials was visually engaging and left visitors like myself with the option to explore topics in further depth. Given the highly European context of display, I wish the exhibition could have further connected the collections to the wider discussions and debates surrounding African arts in Europe outside the walls of the museum. However, the exhibition does raise important points for the future of cross-cultural display. It shows that direct comparison can be a useful tool for asking questions, making connections, and prompting discussion. In this way, Beyond Compare does move beyond simple hierarchical comparison to more complex levels of conversation.

\section{References Cited}

Chapuis, Julien, Jonathan Fine and Paola Ivanov, eds. 2017. Beyond Compare: Art From Africa in the Bode Museum. Berlin: Edition Braus.

Danto, Arthur, et. al. 1988. Art/artifact: African Art in Anthropology Collections. New York: Center for African Art.

Monroe, John Warne. 2018. “Picasso Primitif.” African Arts 51 (4): 92-94.

Rubin, William, ed. 1984 "Primitivism" in 20th Century Art: Affinity of the Tribal and the Modern. New York: Museum of Modern Art.

Sarr, Felwine, and Bénédicte Savoy. 2018. "The Restitution of African Cultural Heritage: Toward a New Relational Ethics.” Translated by Drew S. Burk. http://restitutionreport2018.com/sarr savoy en.pdf

Kristin Otto is a Research Associate of the Mathers Museum of World Cultures, a National Science Foundation Graduate Fellow, and a Ph.D. candidate in the Department of Anthropology at Indiana University. She has curated two museum exhibitions. Shapes of the Ancestors: Bodies, Animals, Art, and Ghanaian Fantasy Coffins was presented in 2018 at the Mathers Museum of World Cultures while Extending Lives: Repair and Damage in African Arts was featured at the Eskenazi Museum of Art in 2017. She has published work in Teaching Sociology and The International Journal of the Inclusive Museum. Her dissertation research focuses on questions of maintenance and repair in material culture. 


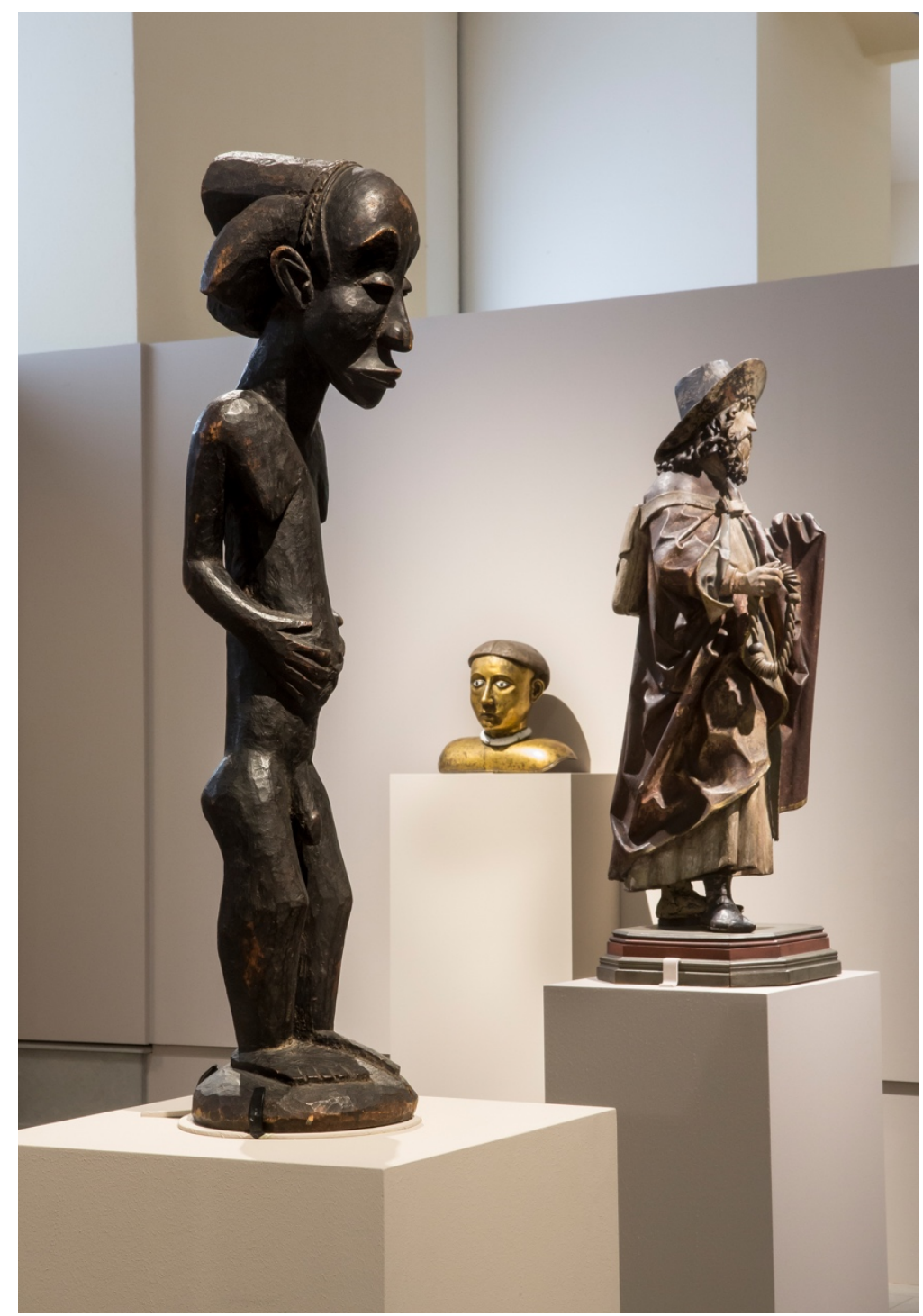

Figure 6. Unvergleichlich: Kunst aus Afrika im Bode-Museum, Ausstellungsansicht, (C) Staatliche Museen zu Berlin / David von Becker.

https://doi.org/10.14434/mar.v13i1.26579 